Open Access

\title{
One stage surgical treatment of aortic valve disease and aortic coarctation with aortic bypass grafting through the diaphragm and aortic valve replacement
}

\author{
Zipu Yu, Shengjun Wu, Chengchen Li, Yu Zou and Liang Ma*
}

\begin{abstract}
Objectives: To validate ascending aorta-lower abdominal aorta bypass grafting treatment for patients with descending aortic coarctation and an aortic valve disease.

Methods: The three patients in whom a descending atypical aortic coarctation was associated with an aortic valve disease were treated with one stage surgical treatment with aortic bypass grafting through the diaphragm and aortic valve replacement in our heart center. Operative technique consisted of performing ascending aorta-lower abdominal aorta bypass grafting through diaphragm muscle and implementing aortic valve replacement. The mean time for extracorporeal circulation and occluding clamp of aorta was recorded. Blood pressure data for pre- and post-operation was measured in the limbs. Computer-enhanced transvenous angiograms of pre- and postoperation were applied for detection of aortic stenosis. The other adverse events were noticed in outpatient service during a follow-up period.

Results: The mean extracorporeal circulation time was $54 \pm 11 \mathrm{~min}$. The mean time for occluding clamp of aorta was $34 \pm 6 \mathrm{~min}$. An arterial pressure gradient was totally corrected after surgical treatment. Post-operation computer-enhanced transvenous angiograms showed the grafts to be open with a fluent flow. The patients had no gastrointestinal tract complications. No adverse event was noticed during a follow-up period in outpatient service.

Conclusions: Treatment of ascending aorta-lower abdominal aorta bypass is advisable for patients with descending aortic coarctation and an aortic valve disease.
\end{abstract}

Keywords: Aortic bypass grafting, Aortic coarctation, Aortic valve disease, One-stage surgical treatment

\section{Background}

Repair of descending atypical coarctation is not an easy operation for its particular location. What's the best surgical treatment for patients with descending aortic coarctation combined with aortic valve disease? Here we will introduce our experience for these cases. Our experience aims at attracting doctors' attention to aortic bypass grafting from the ascending aorta to lower abdominal aorta as a surgical alternative which will allow an adequate correction of abnormal hemodynamics in patients of this kind.

\footnotetext{
* Correspondence: maliang99@yahoo.com

Department of Cardiac Surgery, 1st Affiliated Hospital, Zhejiang University, 79 Qingchun road, Hangzhou, Zhejiang, China
}

\section{Methods}

\section{Patients}

From March in 2009 to October in 2014, 3 adult men patients were admitted to our center with descending aortic coarctation combined with aortic valve disease at the Department of Cardiovascular and Thoracic Surgery, the First Affiliated Hospital, College of Medicine, Zhejiang University, Hangzhou, China. All patients underwent preoperative assessment including laboratory examination, ultrasonography, thoracic and abdominal computed tomographic angiography (CTA) (Fig. 1). Institutional Review Board approval and informed consent from the patients were obtained to perform one-stage surgical treatment of aortic bypass grafting and aortic valve replacement. 

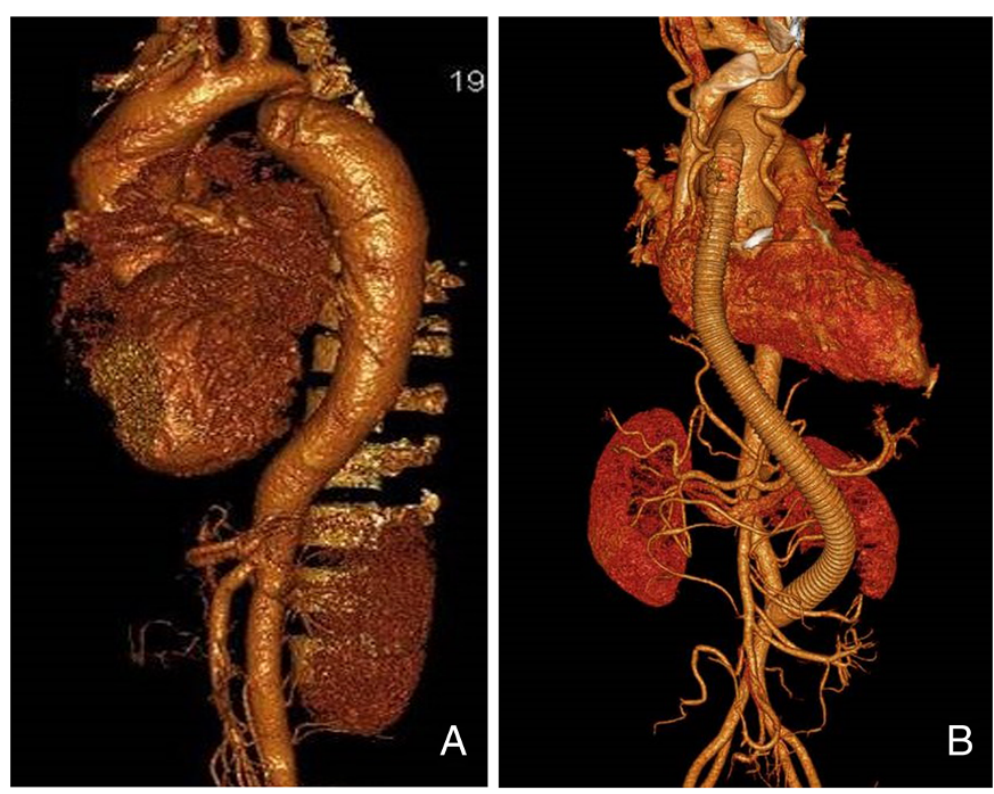

Fig. 1 Preoperative thoracic and abdominal computed tomographic angiography (CTA) showing a descending atypical coarctation (a). Postoperative thoracic and abdominal CTA showing the excellent fluent flow of the aorta-lower abdomiml aorta bypass graft (b)

\section{Operative technique}

The patient, under general anesthesia, was placed in the supine position with the head slightly elevated. A midline incision in the sternum was made to expose the heart. Extracorporeal circulation was set up to perform aortic valve replacement. Pathological aortic valve was replaced with Carbomedics mechanical valve. After recover of heartbeating, extracorporeal circulation was withdrawn. A midline incision in the abdomen was made to isolate the abdominal aorta between renal artery and common iliac artery. A crimped woven vascular prosthesis $16 \mathrm{~mm}$ in diameter was elected in accordance with diameter magnitude of abdominal aorta. With the aid of a partially occluding clamp, the graft was sniped with a bevel connection and anastomosed end-to-side to the distal abdominal aorta isolated previously. The course of the graft passed the liver anteriorly and transversed mesocolon posteriorly, traversd across the root segment of omentum majus, and then was scheduled to head upward through a hole cut in the diaphragm muscle, passed the heart anteriorly in a gentle curve to get to ascending aorta. Finally it was anastomosed with ascending aorta in the end-to-side manner (Fig. 2). The prosthesis was allowed to be filled with blood and expelled the air trapped in the graft. Then the proximal clamp was removed, the covering of the distal anastomosis with peritoneum and the routine closure of the incision were performed at last. All patients take warfarin all their life.

Caution should be paid to details, such as proper tightness of hole cut in the diaphragm muscle to avoid diaphragmatic hernia, careful handle not to give rise to
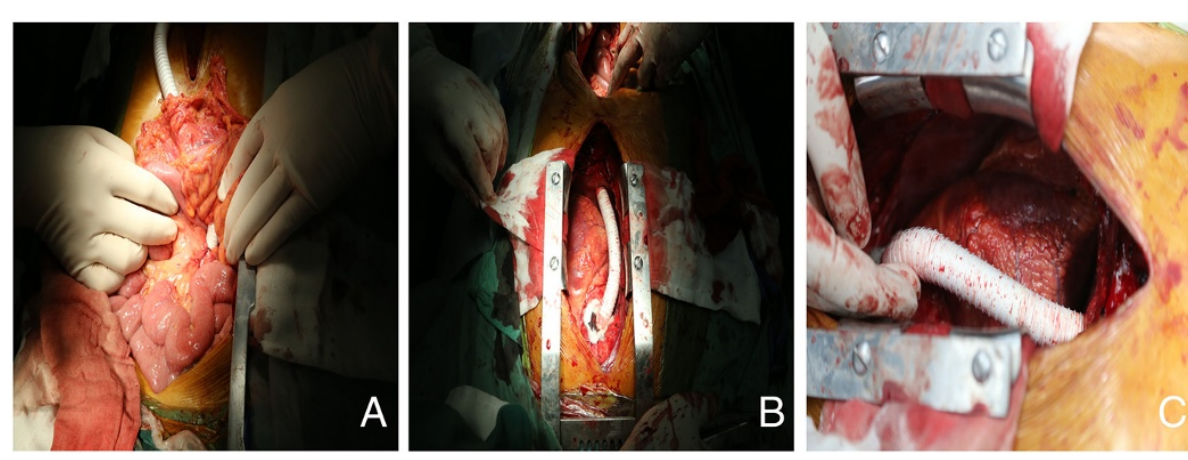

Fig. 2 The aorta-lower abdomiml aorta bypass graft procedure. End-to-side graft-to-distal abdominal aorta anastomosis and end-to-side graft-to ascending aorta anastomosis is performed $(\mathbf{a}, \mathbf{c})$. The course of the graft traversed through a hole cut into the diaphragm muscle (b) 
injury of intra-abdominal organ and appropriate fixation of graft in case of intestinal adhesion.

\section{Results}

The clinical characteristics and outcomes of all patients are summarized in Table 1.

The mean extracorporeal circulation time was $54 \pm 11$ min. The mean time for occluding clamp of aorta was $34 \pm 6 \mathrm{~min}$. No operative mortality was noted. An arterial pressure gradient in the limbs was totally corrected.

Recent computer-enhanced transvenous angiograms showed the grafts to be open with a fluent flow (Fig. 1). During a follow-up period, no gastrointestinal tract complications were noticed in patients.

\section{Discussion}

Coarctation of the aorta $(\mathrm{CoA})$ is typically a narrowing of the thoracic aorta just distal to the left subclavian artery. The treatment for aortic coarctation has undergone a long time development since the first time Crafoord reported such case. It is a congenital vascular malformation disease, almost accouting for 5-8 \% of all congenital heart diseases, which is frequently accompanied with atrial septal defect and ventricular septal defect [1]. Aortic coarctation concomitant with aortic valve disease is scarce, always combined with congenital cardiovascular abnormalities for most cases [2, 3].

Treatment options include surgery, balloon angioplasty and endovascular stenting. Stent implantation has gained great success and become a widely accepted therapeutic option for $\mathrm{CoA}$ in children and adults during the past decades [4-12]. However, serious concerns still remain permanently in the interventional treatment of CoA. During the intermediate-term and long-term follow-ups, several studies indicated that the incidence of re-intervention varied between 6 and $20 \%$ after stent implantation [13-19]. Apart from this, the rupture of the aortic wall was commonly observed in old patients with decreased aortic wall compliance and children with

Table 1 the clinical characteristics and outcomes of patients

\begin{tabular}{llll}
\hline Patient & 1 & 2 & 3 \\
\hline Age(year) & 47 & 39 & 48 \\
Follow-up(month) & 70 & 54 & 5 \\
$\begin{array}{l}\text { Outcome } \\
\begin{array}{l}\text { Pre-operation upper-limb } \\
\text { blood pressure(mm Hg) }\end{array}\end{array}$ & $125 / 65$ & $135 / 65$ & $145 / 50$ \\
$\begin{array}{l}\text { Pre-operation lower-limb } \\
\text { blood pressure(mm Hg) }\end{array}$ & $100 / 55$ & $110 / 50$ & $125 / 45$ \\
$\begin{array}{l}\text { Post-operation upper-limb } \\
\text { blood pressure(mm Hg) }\end{array}$ & $125 / 65$ & $125 / 80$ & $130 / 80$ \\
$\begin{array}{l}\text { Post-operation lower-limb } \\
\text { blood pressure(mm Hg) }\end{array}$ & $130 / 70$ & $130 / 80$ & $130 / 75$ \\
\hline
\end{tabular}

a vascular pathology state. Although procedure-related technical complications have decreased, even if rarely, complications may still be observed.

On the contrary, surgical correction is usually recommended for its wonderful results in increasing diameters of coarctation of the aorta and low re-intervention rate [20]. As reported by Brown et al. [21], surgical repair of coarctation produces lasting results in the majority of the patients and remains the gold standard treatment for CoA. Currently, no consensus has been reached for the best treatment of complex coarctation. Coarctation in association with other cardiac pathology can be treated with a one-stage or two-stage approach. Someone puts forward the viewpoint that it should be treated for stages, aortic valve disease treatment followed by aortic coarctation treatment about 2 months later [22]. It is inclined to adopt the one-stage surgical treatment for these cases with the development of surgical techniques and extracorporeal circulation. Classic surgical operations for this include anatomic repair or extraanatomic bypass grafting. The former operation needs completely isolation of aorta, which may bring out massive haemorrhage. The later operation has chances of pseudoaneurysm. As far as the recurrence of coarctation is concerned, there is no statistic differences between them [23]. The latter surgical procedure is more fit for adults, in whom stent implantation has not so excellent effectiveness. Several open techniques of CoA repair have been described, which included extra-anatomic bypass, resection with end-to-end anastomosis (REE) and resection and interposition graft (RIPG). Bouchart et al. described 35 patients, in whom most were treated with REE [24]. Duara et al. had 46 open repair cases including 27 REE and 13 RIPG, both of which produced a favourable therapeutic effect [25]. Roselli compared 60 endovascular repairs with 40 open repairs, which indicated that open techniques of $\mathrm{CoA}$ repair was associated low risk [26]. Other studies also reported low perioperative major morbidity and no repairrelated mortality with open surgical techniques [27, 28]. However, conventional anatomic repair may be complicated by the need for extensive mobilization of the aorta, control of blood vessels, the possibility of parenchymal lung injury, damage to the recurrent laryngeal or phrenic nerves, the chances of chylothorax and spinal cord ischemia. The most feared complication of aortic surgery is paraplegia and risk of spinal cord injury, which increases with prolonged aortic cross-clamp time and patient age [29].

One-stage surgical treatment of extraanatomic bypass grafting could increase effectiveness and bring down cost, risk and suffering for patients. Cooley and Norman adopt the use of a bypass graft between the ascending aorta and the subdiaphragmatic portion of the upper abdominal aorta for aortic coarctation in children in 1975. 
Use of this operation skills was also reported by Siderys $\mathrm{H}$ and Levy Praschker BG [30, 31]. In order to avoid the risk of the anatomic repair operations, our preferred technique in adults is ascending-to-infrarenal abdominal aorta bypass grafting, which will not block the blood flow for kidney during the opration. As a result, this treatment reduce the chances of injuries for kidney. In our center during past decades, we have been using ascending-to-infrarenal abdominal aorta by-pass grafting mainly under circumstances for descending aortic coarctation combined with heart valve disease. Advantages for this operation include: (1) completely exposure of surgical field, making anastomosis and hemostasis easier in comparison with ascending-to-descending aortic bypass. (2) not movement of heart to keep stabilities of hemodynamics. (3) avoiding hazard of spinal cord ischemia due to aortic cross-clamping. (4) The prosthesis is placed with a gentle curve, thereby avoiding graft obstruction. (5) The distal anastomosis is embedded in a retroperitoneal position and covered with peritoneum, which decreases the risk of fistula formation and other complications in patients. Disadvantages include: (1) two operation incisions. (2) gastrointestinal function change and intestinal adhesion or obstruction if improper treatment, which were not found in our cases.

The long-term results for our patients are satisfactory. We did not document adhesions and compressions in any patient which points to the safety of the ascendingto-infrarenal abdominal aorta by-pass grafting.

\section{Conclusions}

In conclusion, one-stage surgical treatment of descending aortic coarctation combined with aortic valve disease represents a safer solution. Knowledge of this method should contribute to the treatment of complex congenital anomalies.

\section{Competing interests}

The authors declare that they have no competing interests.

\section{Authors' contributions}

ZY and SW carried out the study. CL and YZ participated in the design of the study and performed the statistical analysis. LM conceived of the study, and participated in its design. ZY draft the manuscript. All authors read and approved the final manuscript.

\section{Acknowledgments}

This project was supported by the Department of Cardiovascular and Thoracic Surgery, the First Affiliated Hospital, College of Medicine, Zhejiang University, Hangzhou, China.

Received: 25 June 2015 Accepted: 5 October 2015

Published online: 10 November 2015

\section{References}

1. Quaegebeur JM, Jonas RA, Weinberg AD, Blackstone EH, Kirklin JW. Outcomes in seriously ill neonates with coarctation of the aorta. A multiinstitutional study. J Thorac Cardiovasc Surg. 1994;108:841-51. discussion 852-844.
2. Morris RJ, Samuels LE, Brockman SK. Total simultaneous repair of coarctation and intracardiac pathology in adult patients. Ann Thorac Surg. 1998;65:1698-702.

3. Turina J, Hippenmeyer-Zingg I, Schonbeck M, Turina M. Severe aortic valve diseases and aortic isthmus stenosis in adults. Incidence, clinical aspects and long-term results of surgical treatment. Z Kardiol. 1997;86:676-83.

4. Johnston TA, Grifka RG, Jones TK. Endovascular stents for treatment of coarctation of the aorta: acute results and follow-up experience. Catheter Cardiovasc Interv. 2004;62:499-505.

5. Cheatham JP. Stenting of coarctation of the aorta. Catheter Cardiovasc Interv. 2001;54:112-25.

6. Shah L, Hijazi Z, Sandhu S, Joseph A, Cao QL. Use of endovascular stents for the treatment of coarctation of the aorta in children and adults: immediate and midterm results. J Invasive Cardiol. 2005;17:614-8.

7. Pedra CA, Fontes VF, Esteves CA, Pilla CB, Braga SL, Pedra SR, et al. Stenting vs. balloon angioplasty for discrete unoperated coarctation of the aorta in adolescents and adults. Catheter Cardiovasc Interv. 2005;64:495-506.

8. Pedra CA, Fontes VF, Esteves CA, Arrieta SR, Braga SL, Justino H, et al. Use of covered stents in the management of coarctation of the aorta. Pediatr Cardiol. 2005;26:431-9.

9. Erdem A, Akdeniz C, Saritas T, Erol N, Demir F, Karaci AR, et al. Cheatham-Platinum stent for native and recurrent aortic coarctation in children and adults: immediate and early follow-up results. Anadolu Kardiyol Derg. 2011;11:441-9.

10. Baykan A, Karagoz T, Celiker A. Endovascular stent implantation for coarctation of the aorta in children and young adults: intermediate follow-up results from Turkey. Turk J Pediatr. 2009;51:116-9.

11. Holzer R, Qureshi S, Ghasemi A, Vincent J, Sievert H, Gruenstein D, et al. Stenting of aortic coarctation: acute, intermediate, and long-term results of a prospective multi-institutional registry-Congenital Cardiovascular Interventional Study Consortium (CCISC). Catheter Cardiovasc Interv. 2010;76:553-63.

12. Krasemann T, Bano M, Rosenthal E, Qureshi SA. Results of stent implantation for native and recurrent coarctation of the aorta-follow-up of up to 13 years. Catheter Cardiovasc Interv. 2011;78:405-12.

13. Chessa M, Carrozza M, Butera G, Piazza L, Negura DG, Bussadori C, et al. Results and mid-long-term follow-up of stent implantation for native and recurrent coarctation of the aorta. Eur Heart J. 2005;26:2728-32.

14. Suarez de Lezo J, Pan M, Romero M, Segura J, Pavlovic D, Ojeda S, et al. Percutaneous interventions on severe coarctation of the aorta: a 21-year experience. Pediatr Cardiol. 2005;26:176-89.

15. Qureshi AM, McElhinney DB, Lock JE, Landzberg MJ, Lang P, Marshall AC. Acute and intermediate outcomes, and evaluation of injury to the aortic wall, as based on 15 years experience of implanting stents to treat aortic coarctation. Cardiol Young. 2007;17:307-18.

16. Forbes TJ, Moore P, Pedra CA, Zahn EM, Nykanen D, Amin Z, et al. Intermediate follow-up following intravascular stenting for treatment of coarctation of the aorta. Catheter Cardiovasc Interv. 2007;70:569-77.

17. Thanopoulos BV, Eleftherakis N, Tzanos K, Skoularigis I, Triposkiadis F. Stent implantation for adult aortic coarctation. J Am Coll Cardiol. 2008;52:1815-6.

18. Hager A, Kanz S, Kaemmerer H, Schreiber C, Hess J. Coarctation Long-term Assessment (COALA): significance of arterial hypertension in a cohort of 404 patients up to 27 years after surgical repair of isolated coarctation of the aorta, even in the absence of restenosis and prosthetic material. J Thorac Cardiovasc Surg. 2007;134:738-45.

19. Wright GE, Nowak CA, Goldberg CS, Ohye RG, Bove EL, Rocchini AP. Extended resection and end-to-end anastomosis for aortic coarctation in infants: results of a tailored surgical approach. Ann Thorac Surg. 2005:80:1453-9.

20. Corno AF, Botta U, Hurni M, Payot M, Sekarski N, Tozzi P, et al. Surgery for aortic coarctation: a 30 years experience. Eur I Cardiothorac Surg. 2001;20:1202-6.

21. Brown ML, Burkhart HM, Connolly HM, Dearani JA, Hagler DJ, Schaff HV. Late outcomes of reintervention on the descending aorta after repair of aortic coarctation. Circulation. 2010;122:581-4.

22. Heinemann MK, Ziemer G, Wahlers T, Kohler A, Borst HG. Extraanatomic thoracic aortic bypass grafts: indications, techniques, and results. Eur J Cardiothorac Surg. 1997;11:169-75.

23. Weber HS, Cyran SE. Initial results and clinical follow-up after balloon angioplasty for native coarctation. Am J Cardiol. 1999;84:113-6. a119. 
24. Bouchart F, Dubar A, Tabley A, Litzler PY, Haas-Hubscher C, Redonnet M, et al. Coarctation of the aorta in adults: surgical results and long-term follow-up. Ann Thorac Surg. 2000;70:1483-8. discussion 1488-1489.

25. Duara R, Theodore S, Sarma PS, Unnikrishnan M, Neelakandhan KS. Correction of coarctation of aorta in adult patients-impact of corrective procedure on long-term recoarctation and systolic hypertension. Thorac Cardiovasc Surg. 2008;56:83-6.

26. Roselli EE, Qureshi A, Idrees J, Lima B, Greenberg RK, Svensson LG, et al. Open, hybrid, and endovascular treatment for aortic coarctation and postrepair aneurysm in adolescents and adults. Ann Thorac Surg. 2012;94:751-6. discussion 757-758.

27. Bauer M, Alexi-Meskishvili W, Bauer U, Alfaouri D, Lange PE, Hetzer R. Benefits of surgical repair of coarctation of the aorta in patients older than 50 years. Ann Thorac Surg. 2001;72:2060-4.

28. Rokkas CK, Murphy SF, Kouchoukos NT. Aortic coarctation in the adult: management of complications and coexisting arterial abnormalities with hypothermic cardiopulmonary bypass and circulatory arrest. J Thorac Cardiovasc Surg. 2002;124:155-61.

29. Grinda JM, Mace L, Dervanian P, Folliguet TA, Neveux JY. Bypass graft for complex forms of isthmic aortic coarctation in adults. Ann Thorac Surg. 1995:60:1299-302.

30. Siderys H, Graffis R, Halbrook H, Kasbeckar V. A technique for management of inaccessible coarctation of the aorta. J Thorac Cardiovasc Surg. 1974;67:568-70

31. Levy Praschker BG, Mordant P, Barreda E, Gandjbakhch I, Pavie A. Long-term results of ascending aorta-abdominal aorta extra-anatomic bypass for recoarctation in adults with 27-year follow-up. Eur J Cardiothorac Surg. 2008:34:805-9.

\section{Submit your next manuscript to BioMed Central and take full advantage of:}

- Convenient online submission

- Thorough peer review

- No space constraints or color figure charges

- Immediate publication on acceptance

- Inclusion in PubMed, CAS, Scopus and Google Scholar

- Research which is freely available for redistribution 